Pacific Journal of Mathematics

COMPLEX CHEBYSHEV ALTERATIONS 


\title{
COMPLEX CHEBYSHEV ALTERATIONS
}

\author{
S. J. POREDA
}

\begin{abstract}
P. Chebyshev's famous Alternation Theorem for best uniform approximation to continuous real valued functions on an interval is generalized to include best approximation to a class of continuous complex valued functions on an ellipse.
\end{abstract}

1. Preliminary remarks and definitions. For a continuous complex valued function $f$ defined on a compact set $E$ in the plane and, for $n \in Z^{+}$, let $p_{n}(f, E)$ denote the polynomial of degree $n$, of best uniform appoximation to $f$ on $E$ and let;

$$
\rho_{n}(f, E)=\max _{z \in E}\left|f(z)-p_{n}(f, E)(z)\right| \cdot
$$

Chebyshev's Alternation Theorem [1, p. 29] states that if $f$ is a continuous real valued function on an interval $[a, b]$, and $p_{n}$ is a polynomial of degree $n, n \in Z^{+}$, then $p_{n}=p_{n}(f,[a, b])$ if and only if, there exists $n+2$ points,

$\left\{x_{i}\right\}_{i=1}^{n+2}, a \leqq x_{1}<x_{2}<\cdots<x_{n+2} \leqq b$, with the property that $\left|f(x)-p_{n}(x)\right|$ attains its maximum on $[a, b]$ at these points and $f\left(x_{i}\right)-p_{n}\left(x_{i}\right)=$ $-\left[f\left(x_{i+1}\right)-p_{n}\left(x_{i+1}\right)\right]$ for $i=1,2, \cdots, n+1$.

The sets we consider here are ellipses which are of course a generalization of intervals. So, for $a \geqq 0$, let $E_{a}=\{z+a / z:|z|=1\}$. Now let $\mathscr{F}_{n}\left(E_{n}\right)$ denote those complex valued functions $f$, not themselves polynomials of degree $n$, continuous on $E_{a}$, having the property that there exists $n+2$ points $\left\{\xi_{k}\right\}_{k=1}^{n+2}$ in $E_{a}$, such that $p_{n}\left(f, E_{n}\right)=$ $p_{n}\left(f,\left\{\xi_{k}\right\}_{k=1}^{n+2}\right)$. It is known [1, p. 22] that there always exists a set $D \subset E_{a}$, consisting of $n+k$ points, $2 \leqq k \leqq n+3$, such that $p_{n}\left(f, E_{a}\right)=p_{n}(f, D)$. Furthermore, to this author's knowledge, every example of best uniform approximation to rational functions on infinite sets in the plane (e.g., [3], [4] and [5]) is one in which such a set consisting of $n+2$ points exists or, can be shown equivalent to such an example.

2. Main theorem. Given $n+2$ points $\left\{\xi_{k}\right\}_{k=1}^{n+2}$ in $E_{a}$ let $z_{k}$ be such that $\xi_{k}=z_{k}+a / z_{k},\left|z_{k}\right|=1$ and if $a=1,0 \leqq \operatorname{Arg} z_{k} \leqq \pi$ for $k=$ $1,2, \cdots, n+2$. The $z_{k}^{\prime}$ s are uniquely determined. Now let

$$
\Phi_{k}=z_{k}^{-n / 2} \prod_{\substack{j=1 \\ j \neq k}}^{n+2}\left[\left(z_{k} z_{j}-a\right) /\left|z_{k} z_{j}-a\right|\right] \text { for }
$$

$k=1,2, \cdots, n+2$ where $0 \leqq \arg z^{1 / 2}<\pi$. 
THEOREM 1. If $f$ is continuous on $E_{a}$ and $p_{n}$ is a polynomial of degree $n, n \in Z^{+}$, then $f \in \mathscr{F}_{n}\left(E_{a}\right)$ and $p_{n}=p_{n}\left(f, E_{a}\right)$ if and only if there exists $n+2$ points $\left\{\xi_{k}\right\}_{k=1}^{n+2}$ in $E_{a}$, with $0 \leqq \operatorname{Arg} \xi_{1}<\operatorname{Arg} \xi_{2}<$ $\cdots<\operatorname{Arg} \xi_{n+2}<2 \pi$ if $a \neq 1$ or $-2 \leqq \xi_{1}<\xi_{2}<\cdots<\xi_{n+2} \leqq 2$ if $a=1$, where $\left|f(\xi)-p_{n}(\xi)\right|$ attains its maximum on $E_{a}$ and, $\left[f\left(\xi_{i}\right)-p_{n}\left(\xi_{i}\right)\right] / \Phi_{i}=$ $-\left[f\left(\xi_{i+1}\right)-p_{n}\left(\xi_{i+1}\right)\right] / \Phi_{i+1}$ for $i=1,2, \cdots, n+1$ where the $\Phi_{i}$ 's are defined in terms of the $\xi_{i}$ 's as above.

Proof. In order to prove our theorem we make use of a lemma which is a reformulation of a result [2] due to T. S. Motzkin and J. L. Walsh.

LEmma. A necessary and sufficient condition that the given numbers $\left\{\sigma_{k}\right\}_{k=1}^{n+2}$ be the deviations of some function $f$ defined on the $n+2$ points $\left\{\xi_{k}\right\}_{k=1}^{n+2}$ and its polynomial of degree $n$ of best uniform approximation to $f$ on these points is that for some $\rho \geqq 0$;

(1) $\left|\sigma_{k}\right|=\rho$ for $k=1,2, \cdots, n+2$ and,

(2) $\arg \sigma_{k}=\arg \omega^{\prime}\left(\xi_{k}\right)+\theta_{0}$ for $k=1,2, \cdots, n+2$ if $\rho>0$ where

$$
\omega(\xi)=\prod_{k=1}^{n+2}\left(\xi-\xi_{k}\right) \text { and } \theta_{0}=\arg \left[\sum_{k=1}^{n+2} f\left(\xi_{k}\right) / \omega^{\prime}\left(\xi_{k}\right)\right] \text {. }
$$

The necessary portion of our theorem will then follow if it is shown that;

$$
\arg \left\{\left[\omega^{\prime}\left(\xi_{i}\right) / \Phi_{i}\right] /\left[\omega^{\prime}\left(\xi_{i+1}\right) / \Phi_{i+1}\right]\right)=\pi \text { for }
$$

$i=1,2, \cdots, n+1$. Now substituting $z_{j}+a / z_{j}$ for $\xi_{j}$ and using the definition of the $\Phi_{j}$ 's we can show the (2.1) is equivalent to;

$$
\arg \left\{\left(z_{i+1}^{n / 2} / z_{i}^{n / 2}\right) \prod_{\substack{j \neq i, i+1 \\ j=1}}^{n+2}\left[\left(z_{i}-z_{j}\right) /\left(z_{i+1}-z_{j}\right)\right]\right\}=0 .
$$

But, (2.2) follows since $z_{i}$ and $z_{i+1}$ are by virtue of their definition adjacent on the unit circle $U\left(\right.$ i.e., $z_{i}$ and $z_{i+1}$ are on a connected arc in $U$ containing none of the other $\left.z_{j^{\prime} \mathrm{s}}\right)$ and since; $\arg \left(z_{i+1} / z_{i}\right)=$ $\left.-2 \arg \left[z_{i}-z_{j}\right) /\left(z_{i+1}-z_{j}\right)\right]$ for $j \neq i, i+1$.

In order to prove the converse of our theorem we simply work backwards and show that; $\arg \left[f\left(\xi_{k}\right)-P_{n}\left(\xi_{k}\right)\right]=\arg \omega^{\prime}\left(\xi_{k}\right)+\theta_{0}$ for some $\theta_{0}$ and $k=1,2, \cdots, n+2$ and apply the aforementioned result of Motzkin and Walsh.

3. Special cases and applications. Chebyshev's Alternation Theorem follows as a special case of Theorem 1 , when $a=1$, since it is known [1, p. 22] that all real functions, not themselves polynomials of degree $n$, continuous on $[-2,2]$ are in the class $\mathscr{F}_{n}([-2,2])$. 
Also of interest because of its simple form is the case where $a=0$ or $E_{a}=U$ is the unit circle and where $n$ is even. In this case our main theorem appears to provide us with a valuable tool in determining if a given function $f$ is in $\mathscr{F}_{2 m}(U)$ and if it is, in finding $p_{2 m}(f, U)$.

CoRollary 1. If $f$ is continuous on $U$ and $p_{2 m}$ is a polynomial of degree $2 m, m \in Z^{+}$, then $f \in \mathscr{F}_{2 m}(U)$ and $p_{2 m}=p_{2 m}(f, U)$ if and only if there exists $2 m+2$ points, $\left\{z_{k}\right\}_{k=1}^{m+2}$, with $0 \leqq \operatorname{Arg} z_{1}<\cdots<\operatorname{Arg}$ $z_{2 m+2}<2 \pi$ where $\left|f(z)-p_{2 m}(z)\right|$ attains its maximum on $U$ and where $\left[f\left(z_{k}\right)-p_{2 m}\left(z_{k}\right)\right] / z_{k}^{m}=-\left[f\left(z_{k+1}\right)-p_{2 m}\left(z_{k+1}\right)\right] / z_{k+1}^{m}$, for $k=1,2, \cdots, 2 m+1$.

Corollary 1 can be used to obtain a recently discovered example of best approximation [3], namely, if $f(z)=(\alpha z+\beta) /(z-a)(1-\bar{a} z)$, $|a|>1$, then;

$$
p_{2 m}(f, U)(z)=\left[\alpha z+\beta-K_{1} z^{2 m}(1-\bar{a} z)^{2}-K_{2}(z-a)^{2}\right] /(z-a)(1-\bar{a} z),
$$

where

$$
K_{1}=(\alpha a+\beta) / a^{2 m}\left(1-|a|^{2}\right)^{2}
$$

and,

$$
K_{2}=\bar{a}(\alpha+\beta \bar{a}) /\left(1-|a|^{2}\right)^{2} .
$$

\section{REFERENCES}

1. G. G. Lorentz, Approximation of Functions, Holt, Rinehart and Winston, 1966.

2. T. S. Motzkin and J. L. Walsh, On the derivative of a polynomial and Chebyshev approximation, Proc. Amer. Math. Soc., 4 (1953), 76-87.

3. S. J. Poreda, An example of best uniform approximation in the complex plane, Notices Amer. Math. Soc., 17 (1970), 569.

4. T. J. Rivlin, Some explicit polynomial approximations in the complex domain, Bull. Amer. Math. Soc., 73 (1967), 467-469.

5. T. J. Rivlin and H. S. Weiss, Some best polynomial approximations in the plane, Duke Math. J., 35 (1968), 475-482.

Received December 4, 1970. This work represents part of the author's doctoral dissertation that was directed by Professor Mishael Zedek at the University of Maryland.

Clark University 



\section{PACIFIC JOURNAL OF MATHEMATICS}

\section{EDITORS}

H. SAMELSON

Stanford University

Stanford, California 94305

C. R. HOBBY

University of Washington

Seattle, Washington 98105
J. DugundJI

Department of Mathematics

University of Southern California

Los Angeles, California 90007

RICHARD ARENS

University of California

Los Angeles, California 90024

\section{ASSOCIATE EDITORS}

E. F. BeCKENBACH

B. H. NeumanN

F. WOLF

K. YosHIDA

\section{SUPPORTING INSTITUTIONS}

UNIVERSITY OF BRITISH COLUMBIA

CALIFORNIA INSTITUTE OF TECHNOLOGY

UNIVERSITY OF CALIFORNIA

MONTANA STATE UNIVERSITY

UNIVERSITY OF NEVADA

NEW MEXICO STATE UNIVERSITY

OREGON STATE UNIVERSITY

UNIVERSITY OF OREGON

OSARA UNIVERSITY
UNIVERSITY OF SOUTHERN CALIFORNIA STANFORD UNIVERSITY

UNIVERSITY OF TOKYO

UNIVERSITY OF UTAH

WASHINGTON STATE UNIVERSITY

UNIVERSITY OF WASHINGTON

AMERICAN MATHEMATICAL SOCIETY

NAVAL WEAPONS CENTER

Printed in Japan by International Academic Printing Co., Ltd., Tokyo, Japan 


\section{Pacific Journal of Mathematics}

\section{Vol. 40, No. $1 \quad$ September, 1972}

Alex Bacopoulos and Athanassios G. Kartsatos, On polynomials

approximating the solutions of nonlinear differential equations........

Monte Boisen and Max Dean Larsen, Prüfer and valuation rings with zero

divisors ..........................................

James J. Bowe, Neat homomorphisms

David W. Boyd and Hershy Kisilevsky, The Diophantine equation

$$
u(u+1)(u+2)(u+3)=v(v+1)(v+2) \ldots \ldots \ldots \ldots \ldots \ldots \ldots
$$

George Ulrich Brauer, Summability and Fourier analysis ...............

Robin B. S. Brooks, On removing coincidences of two maps when only one,

rather than both, of them may be deformed by a homotopy ............

Frank Castagna and Geert Caleb Ernst Prins, Every generalized Petersen

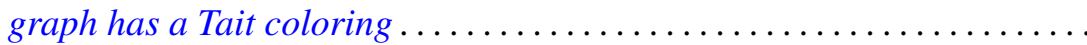

Micheal Neal Dyer, Rational homology and Whitehead products ..........

John Fuelberth and Mark Lawrence Teply, The singular submodule of a

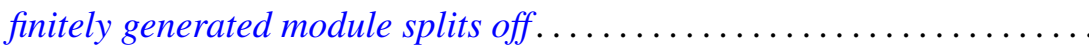

Robert Gold, $\Gamma$-extensions of imaginary quadratic fields ............ 83

Myron Goldberg and John W. Moon, Cycles in k-strong tournaments.......

Darald Joe Hartfiel and J. W. Spellmann, Diagonal similarity of irreducible

matrices to row stochastic matrices...............

Wayland M. Hubbart, Some results on blocks over local fields ..

Alan Loeb Kostinsky, Projective lattices and bounded homomorphisms....

Kenneth O. Leland, Maximum modulus theorems for algebras of operator

valued functions ...

Jerome Irving Malitz and William Nelson Reinhardt, Maximal models in the

language with quantifier "there exist uncountably many" ..

John Douglas Moore, Isometric immersions of space forms in space

forms.

Ronald C. Mullin and Ralph Gordon Stanton, A map-theoretic approach to

Davenport-Schinzel sequences ....................

Chull Park, On Fredholm transformations in Yeh-Wiener space. .

Stanley Poreda, Complex Chebyshev alterations ..............

Ray C. Shiflett, Extreme Markov operators and the orbits of Ryff. ...

Robert L. Snider, Lattices of radicals .....................

Ralph Richard Summerhill, Unknotting cones in the topological

category ................................

Charles Irvin Vinsonhaler, A note on two generalizations of $\mathrm{QF}-3 \ldots \ldots 229$

William Patterson Wardlaw, Defining relations for certain integrally

parameterized Chevalley groups...................

William Jennings Wickless, Abelian groups which admit only nilpotent

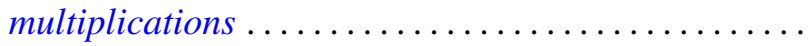

